\title{
Predictors of clinically significant quality of life impairment in Parkinson's disease
}

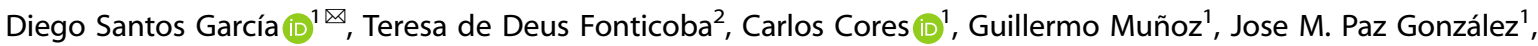 \\ Cristina Martínez Miró ${ }^{1}$, Ester Suárez ${ }^{2}$, Silvia Jesús ${ }^{3,4}$, Miquel Aguilar ${ }^{5}$, Pau Pastor ${ }^{5}$, Lluis Planellas ${ }^{6}$, Marina Cosgaya ${ }^{7}$, \\ Juan García Caldentey ${ }^{8}$, Nuria Caballol ${ }^{9}$, Inés Legarda ${ }^{10}$, Jorge Hernández Vara $\mathbb{D}^{11}$, Iria Cabo ${ }^{12}$, Luis López Manzanares ${ }^{13}$,

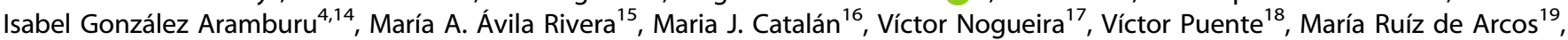 \\ Carmen Borrué ${ }^{20}$, Berta Solano Vila ${ }^{21}$, María Álvarez Sauco ${ }^{22}$, Lydia Vela $\mathbb{D}^{23}$, Sonia Escalante (D) $^{24}$, Esther Cubo ${ }^{25}$, \\ Francisco Carrillo Padilla ${ }^{26}$, Juan C. Martínez Castrillo (D) $^{27}$, Pilar Sánchez Alonso ${ }^{28}$, Maria G. Alonso Losada ${ }^{29}$, Nuria López Ariztegui ${ }^{30}$, \\ Itziar Gastón ${ }^{31}$, Pedro Clavero ${ }^{31}$, Jaime Kulisevsky (D,32, Marta Blázquez Estrada ${ }^{33}$, Manuel Seijo ${ }^{12}$, Javier Rúiz Martínez ${ }^{34}$, \\ Caridad Valero $^{35}$, Mónica Kurtis ${ }^{36}$, Oriol de Fábregues $\mathbb{B D}^{11}$, Jessica González Ardura ${ }^{37}$, Carlos Ordás ${ }^{38}$, Luis M. López Díaz ${ }^{39}$, \\ Darrian McAfee ${ }^{40}$, Pablo Martinez-Martin ${ }^{4}$, Pablo Mir (iD ${ }^{3,4}$ and COPPADIS Study Group*
}

Quality of life (QOL) plays an important role in independent living in Parkinson's disease (PD) patients, being crucial to know what factors impact QoL throughout the course of the disease. Here we identified predictors of QoL impairment in PD patients from a Spanish cohort. PD patients recruited from 35 centers of Spain from the COPPADIS cohort from January 2016, to November 2017, were followed up during 2 years. Health-related QoL (HRQoL) and global QoL (GQoL) were assessed with the 39-item Parkinson's disease Questionnaire (PDQ-39) and the EUROHIS-QOL 8-item index (EUROHIS-QOL8), respectively, at baseline (V0) and at 24 months \pm 1 month (V2). Clinically significant QoL impairment was defined as presenting an increase (PDQ-39SI) or decrement (EUROHIS-QOL8) at V2 $\geq 10 \%$ of the score at baseline (V0). A comparison with a control group was conducted for GQoL. GQoL did not change significantly in PD patients $(N=507 ; p=0.686)$ or in the control group $(N=119 ; p=0.192)$. The mean PDQ-39SI was significantly increased in PD patients $(62.7 \pm 8.5$ years old; $58.8 \%$ males; $N=500$ ) by $21.6 \%$ (from $16.7 \pm 13$ to $20.3 \pm 16.4 ; p<0.0001$ ) at V2. Ninety-three patients (18.6\%) presented a clinically significant HRQoL impairment at V2. To be younger (OR $=0.896 ; 95 \% \mathrm{Cl}$ $0.829-0.968 ; p=0.006)$, to be a female $(\mathrm{OR}=4.181 ; 95 \% \mathrm{Cl} 1.422-12.290 ; p=0.009)$, and to have a greater increase in $\mathrm{BDI}-\mathrm{II}(\mathrm{Beck}$ Depression Inventory-II) $(\mathrm{OR}=1.139 ; 95 \% \mathrm{Cl} 1.053-1.231 ; p=0.001)$ and NMSS (Non-Motor Symptoms Scale) $(\mathrm{OR}=1.052 ; 95 \% \mathrm{Cl}$ 1.027-1.113; $p<0.0001$ ) total scores from V0 to V2 were associated with clinically significant HRQoL impairment at the 2-year follow-up (Hosmer-Lemeshow test, $p=0.665 ; R^{2}=0.655$ ). An increase in $\geq 5$ and $\geq 10$ points of BDI-II and NMSS total score at V2 multiplied the probability of presenting clinically significant $\mathrm{HRQOL}$ impairment by $5(\mathrm{OR}=5.453 ; 95 \% \mathrm{Cl} 1.663-17.876 ; p=0.005)$ and $8(\mathrm{OR}=8.217 ; 95 \% \mathrm{Cl}, 2.975-22.696 ; p=0.002)$, respectively. In conclusion, age, gender, mood, and non-motor impairment were associated with clinically significant $\mathrm{HRQ}$ oL impairment after the 2-year follow-up in PD patients.

npj Parkinson's Disease (2021) 7:118; https://doi.org/10.1038/s41531-021-00256-w

\section{INTRODUCTION}

Parkinson's disease (PD) is a complex disorder in which different motor and non-motor symptoms (NMS) can be present with a frequency and severity that varies among patients over time ${ }^{1}$. Both motor and NMS are important because they negatively impact the patient's quality of life (QoL). Different studies have analyzed what factors contribute to a poor QoL in PD patients ${ }^{2-13}$. Recently, we observed that NMS burden, mood, and gait problems were the most relevant factors affecting health-related (HRQoL) and global perceived QoL (GQoL) in non-demented PD patients from the Spanish cohort COPPADIS ${ }^{14}$. These results aligned with other cross-sectional studies observations ${ }^{15-17}$. However, with

\footnotetext{
${ }^{1}$ CHUAC, Complejo Hospitalario Universitario de A Coruña, A Coruña, Spain. ${ }^{2}$ CHUF, Complejo Hospitalario Universitario de Ferrol, A Coruña, Spain. ${ }^{3}$ Unidad de Trastornos del Movimiento, Servicio de Neurología y Neurofisiología Clínica, Instituto de Biomedicina de Sevilla, Hospital Universitario Virgen del Rocío/CSIC/Universidad de Sevilla, Seville, Spain. ${ }^{4}$ CIBERNED (Centro de Investigación Biomédica en Red sobre Enfermedades Neurodegenerativas), Álava, Spain. ${ }^{5}$ Hospital Universitari Mutua de Terrassa, Terrassa, Barcelona, Spain. ${ }^{6}$ Neurología, Clínica del Pilar, Barcelona, Spain. ${ }^{7}$ Hospital Clínic de Barcelona, Barcelona, Spain. ${ }^{8}$ Centro Neurológico Oms 42, Palma de Mallorca, Spain. ${ }^{9}$ Consorci Sanitari Integral, Hospital Moisés Broggi, Sant Joan Despí, Barcelona, Spain. ${ }^{10}$ Hospital Universitario Son Espases, Palma de Mallorca, Spain. ${ }^{11}$ Hospital Universitario Vall d'Hebron, Barcelona, Spain. ${ }^{12}$ Complejo Hospitalario Universitario de Pontevedra (CHOP), Pontevedra, Spain. ${ }^{13}$ Hospital Universitario La Princesa, Madrid, Spain. ${ }^{14}$ Hospital Universitario Marqués de Valdecilla, Santander, Spain. ${ }^{15}$ Consorci Sanitari Integral, Hospital General de L'Hospitalet, L'Hospitalet de Llobregat, Barcelona, Spain. ${ }^{16}$ Hospital Universitario Clínico San Carlos, Madrid, Spain. ${ }^{17}$ Hospital Da Costa, Burela, Lugo, Spain. ${ }^{18}$ Hospital del Mar, Barcelona, Spain. ${ }^{19}$ Hospital Universitario Virgen Macarena, Sevilla, Spain. ${ }^{20}$ Hospital Infanta Sofía, Madrid, Spain. ${ }^{21}$ Institut d'Assistència Sanitària (IAS) - Institut Català de la Salut, Girona, Spain. ${ }^{22}$ Hospital General Universitario de Elche, Elche, Spain. ${ }^{23}$ Fundación Hospital de Alcorcón, Madrid, Spain. ${ }^{24}$ Hospital de Tortosa Verge de la Cinta (HTVC), Tortosa, Tarragona, Spain. ${ }^{25}$ Complejo Asistencial Universitario de Burgos, Burgos, Spain. ${ }^{26}$ Hospital Universitario de Canarias, San Cristóbal de la Laguna, Santa Cruz de Tenerife, Spain. ${ }^{27}$ Hospital Universitario Ramón y Cajal, IRYCIS, Madrid, Spain. ${ }^{28}$ Hospital Universitario Puerta de Hierro, Madrid, Spain. ${ }^{29}$ Hospital Álvaro Cunqueiro, Complejo Hospitalario Universitario de Vigo (CHUVI), Vigo, Spain. ${ }^{30}$ Complejo Hospitalario de Toledo, Toledo, Spain. ${ }^{31}$ Complejo Hospitalario de Navarra, Pamplona, Spain. ${ }^{32}$ Hospital de Sant Pau, Barcelona, Spain. ${ }^{33}$ Hospital Universitario Central de Asturias, Oviedo, Spain. ${ }^{34}$ Hospital Universitario

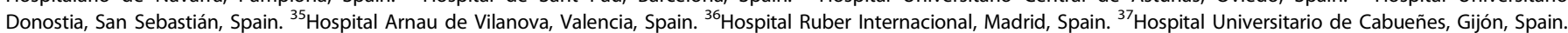
${ }^{38}$ Hospital Rey Juan Carlos, Madrid, Spain, Madrid, Spain. ${ }^{39}$ Complejo Hospitalario Universitario de Orense (CHUO), Orense, Spain. ${ }^{40}$ Univeristy of Pennsylvania, Pennsylvania, USA. *A list of authors and their affiliations appears at the end of the paper. ${ }^{凶}$ email: diegosangar@yahoo.es
} 
PDQ-39SI PD patients ( $N=500)$

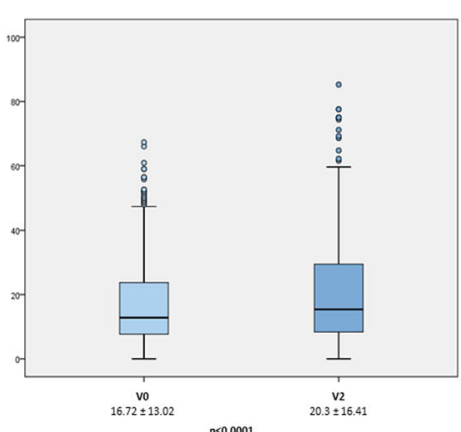

Controls ( $\mathrm{N}=122)$ PQ-10

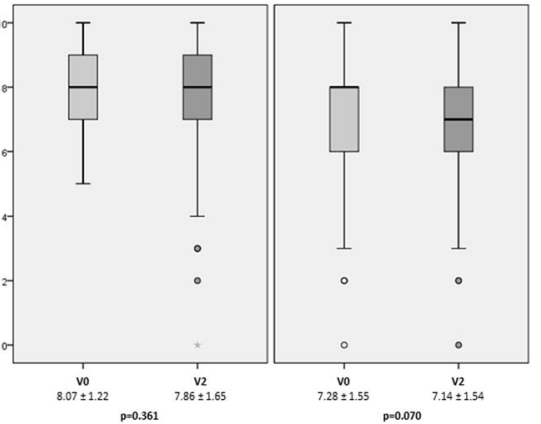

EUROHIS-QOL8 Controls $(\mathrm{N}=119) \quad$ PD patients ( $\mathrm{N}=507)$

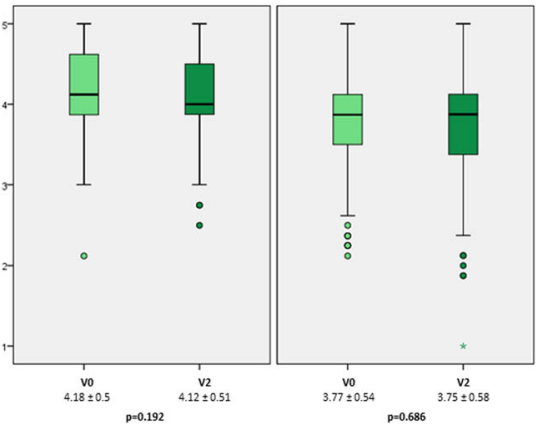

Fig. 1 Change in PDQ-39SI, PQ-10, and EUROHIS-QOL8 scores from V0 (baseline) to V2 (2 year \pm 1 month) in PD patients and/or controls. Data are presented as box plots, with the box representing the median and the two middle quartiles (25-75\%). $p$-values were computed using the Wilcoxon-signed rank test. Mild outliers (O) are data points that are more extreme than Q1 - $1.5 *$ IQR or Q3 + $1.5 *$ IQR. EUROHIS-QOL8, European Health Interview Survey-Quality of Life 8-Item Index; PDQ-39SI, 39-item Parkinson's Disease Quality of Life Questionnaire Summary Index.

regard to how the QoL of PD changes throughout the course of the disease, there is much less information ${ }^{18-23}$ and prospective longitudinal studies are needed. In clinical practice, it is important to know what factors worsen PD patients' QoL with the intention to carry out effective interventions. Known information limited by factors from the studies such as the sample size, the differences between scales used for assessing QoL, the different types of QoL assessed, being a non-multicenter study, the absence of a control group, and/or the lack of a global evaluation including different aspects that could impact on QoL ${ }^{18-23}$. In addition, the impact of some complications on QoL in advanced PD has been analyzed before $^{24,25}$. However, it is not clear what the significance of shortterm changes in QoL is in early PD patients or what factors contribute to it when an extensive assessment considering motor and NMS is performed ${ }^{26}$. It is remarkable that NMS occur not only in advanced but also in the early stages of PD. Some symptoms, for example, olfactory deficit, constipation, rapid-eyemovement sleep behavior disorder, and depression, can even precede the appearance of motor symptoms by many years ${ }^{1}$. By the contrary, others such as psychosis or dementia are not present. The first years are conditioned by the acceptance of the diagnosis, but in general, the patient has greater autonomy. In this context, it is essential to know what influences the changes in the PD patient QoL perception with the intention of being able to act as soon as possible.

The aim of the present study was to (1) analyze the change in HRQoL and GQoL in PD patients from the COPPADIS cohort after the 2-year follow-up, (2) to compare with a control group, and (3) to identify predictors of clinically significant QoL impairment in the PD group. Finally, a subanalysis was conducted in a subgroup of patients with early PD ( $\leq 5$ years of disease duration).

\section{RESULTS}

\section{Changes in assessments from V0 to V2}

After the 2-year follow-up, GQoL did not change significantly in PD patients (from PQ- $10_{\mathrm{v} 0}$ of $7.28 \pm 1.55$ to $\mathrm{PQ}-10_{\mathrm{V} 2}$ of $7.14 \pm 1.54$ $[N=503 ; p=0.070]$; from EUROHIS-QOL8 ${ }_{\mathrm{V}}$ of $3.77 \pm 0.54$ to EUROHIS-QOL $8_{\mathrm{V} 2}$ of $3.75 \pm 0.58[N=507 ; p=0.686]$ ) or in the control group (from PQ-10 $\mathrm{v}_{\mathrm{v}}$ of $8.07 \pm 1.22$ to $\mathrm{PQ}-10_{\mathrm{V} 2}$ of $7.86 \pm$ $1.65[N=122 ; p=0.361]$; from EUROHIS-QOL8 $\mathrm{V}_{\mathrm{V}}$ of $4.18 \pm 0.5$ to EUROHIS-QOL $8_{\mathrm{V} 2}$ of $4.12 \pm 0.51$ [ $N=119 ; p=0.192$ ] (Fig. 1). The mean PDQ-39SI was significantly increased in PD patients $(62.7 \pm$ 8.5 years old; $58.8 \%$ males; $N=500$ ) by $21.6 \%$ (from $16.72 \pm 13.02$ to $20.3 \pm 16.41 ; p<0.0001$ ) at V2 (Table 1 and Fig. 1). By domains, the score of all domains of the PDQ-39SI at V2 was significantly higher than at V0 except for domain 4 (stigmatization) (Table 1).
The change in the score of other scales from V0 to V2 in PD patients and controls is shown in Table 1.

\section{Patients with vs without clinically HRQoL impairment}

Although 291 PD patients (58.2\%) presented an increase in the PDQ-39SI score after the 2-year follow-up, only 93 (18.6\%) presented a clinically significant HRQoL impairment at V2. Differences in change from V0 to V2 of UPDRS-III, UPDRS-IV, FOGQ, NMSS, BDI-II, PDSS, NPI, VAS-PAIN, VASF-physical, VASFmental, and ADLS scores between patients with and without clinically significant HRQoL impairment were observed (Table 2). Specifically, PD patients who presented at the 2-year follow-up a clinically significant $\mathrm{HRQOL}$ impairment presented a $97.3 \%$ increase of the NMS burden (NMSS total score from $29.2 \pm 25.87$ to $57.84 \pm 46.73$ [ $p<0.0001]$ ) compared to $8.6 \%$ in those patients who did not (NMSS total score from $48.38 \pm 38.59$ to $52.53 \pm 41.35$ $[p=0.003]$ ) (Fig. 2A). By domains, the most significant differences were observed for sleep/fatigue $(p<0.0001)$ and mood/apathy $(p<0.0001)$ (Table 2 and Fig. 2B). Moderate correlations were observed between the change from V0 to V2 in the PDQ-39SI score and the score in FOGQ $(r=0.34 ; p<0.0001)$, NMSS $(r=0.41$; $p<0.0001)$, BDI-II $(r=0.33 ; p<0.0001)$ and ADLS $(r=-0.40 ; p<$ 0.0001) (Supplementary Table 1).

\section{Predictors of clinically HRQoL impairment}

To be younger (OR $=0.896 ; 95 \% \mathrm{Cl} 0.829-0.968 ; p=0.006)$, to be a female $(\mathrm{OR}=4.181 ; 95 \% \mathrm{Cl} 1.422-12.290 ; p=0.009)$, and to have a greater increase in BDI-II $(\mathrm{OR}=1.139 ; 95 \% \mathrm{Cl} 1.053-1.231$; $p=0.001)$ and NMSS $(\mathrm{OR}=1.052 ; 95 \% \mathrm{Cl} 1.027-1.113 ; p<0.0001)$ total scores from V0 to V2 were associated with clinically significant HRQoL impairment at the 2-year follow-up, after adjustment to many covariates (Hosmer-Lemeshow test, $p=$ $0.665 ; R^{2}=0.655$ ) (Table 3). Specifically, an increase in $\geq 5$ and $\geq 10$ points of BDI-II and NMSS total score at V2 multiplied the probability of presenting a clinically significant $\mathrm{HRQ}$ L impairment by $5(\mathrm{OR}=5.453 ; 95 \% \mathrm{Cl} 1.663-17.876 ; p=0.005)$ and $8(\mathrm{OR}=$ $8.217 ; 95 \% \mathrm{Cl} 2.975-22.696 ; p=0.002)$, respectively. When ADLS was included in the model (ADLS at V0 and the change in ADLS score from V0 to V2), only a greater increase in BDI-II (OR = 1.148; $95 \%$ Cl 1.057-1.258; $p=0.001$ ), NMSS (Non-Motor Symptoms Scale) $(\mathrm{OR}=1.056 ; 95 \% \mathrm{Cl} 1.029-1.083 ; p<0.0001)$ and NPI $(\mathrm{OR}=$ $1.072 ; 95 \% \mathrm{Cl}, 1.001-1.147 ; p=0.046)$ total scores and a decrease in ADLS score $(\mathrm{OR}=0.884 ; 95 \% \mathrm{Cl} 0.820-0.954 ; p<0.0001)$ from V0 to V2 were associated with clinically significant HRQoL impairment at the 2-year follow-up (Hosmer-Lemeshow test, $p=0.621 ; R^{2}=0.718$ ). 
Table 1. Changes in motor and non-motor symptoms, disability, and quality of life in PD patients and/or controls from V0 (baseline) to V2 (2 years \pm 1 month).

\begin{tabular}{|c|c|c|c|c|c|c|}
\hline & PD patients V0 & PD patients V2 & $p_{\mathrm{a}}$ & Controls V0 & Controls V2 & $p_{\mathrm{b}}$ \\
\hline Stage 1 & 22.7 & 13.3 & & & & \\
\hline Stage $3-5$ & 9.3 & 9.7 & & & & \\
\hline UPDRS-III (OFF) & $21.92 \pm 10.53$ & $25.26 \pm 12.19$ & $<0.0001$ & N. A. & N. A. & N. A. \\
\hline LEDD & $577.48 \pm 412.09$ & $767.56 \pm 307.1$ & $<0.0001$ & N. A. & N. A. & \\
\hline Number of non-antipark. drugs & $2.35 \pm 2.38$ & $3.08 \pm 2.65$ & $<0.0001$ & $2.04 \pm .2 .16$ & $2.76 \pm 2.35$ & 0.001 \\
\hline PD-CRS & $92 \pm 15.65$ & $90.26 \pm 18.07$ & $<0.0001$ & $99.65 \pm 13.56$ & $99.68 \pm 13.73$ & 0.744 \\
\hline NMSS & $45.08 \pm 37.62$ & $53.55 \pm 42.28$ & $<0.0001$ & $14.74 \pm 18.72$ & $14.65 \pm 21.82$ & 0.428 \\
\hline BDI-II & $8.28 \pm 6.9$ & $8.54 \pm 7.48$ & 0.472 & $4.56 \pm 5.46$ & $4.31 \pm 5.5$ & 0.776 \\
\hline VASF - physical & $2.86 \pm 2.67$ & $3.17 \pm 2.8$ & 0.010 & $1.52 \pm 2.35$ & $1.29 \pm 2.12$ & 0.103 \\
\hline VASF - mental & $2.09 \pm 2.51$ & $2.20 \pm 2.61$ & 0.538 & $1.29 \pm 2.09$ & $1.03 \pm 1.97$ & 0.273 \\
\hline ADLSL & $88.58 \pm 10.19$ & $84.26 \pm 13.38$ & $<0.0001$ & $98.87 \pm 6.65$ & $99.52 \pm 2.15$ & 0.285 \\
\hline PDQ-39SI & $16.72 \pm 13.02$ & $20.3 \pm 16.41$ & $<0.0001$ & N. A. & N. A. & N. A. \\
\hline Mobility & $16.28 \pm 19.2$ & $21.31 \pm 22.5$ & $<0.0001$ & & & \\
\hline Activities of daily living & $17.83 \pm 18.83$ & $21.82 \pm 21.37$ & $<0.0001$ & & & \\
\hline Emotional well-being & $20.92 \pm 19.52$ & $23.53 \pm 23.45$ & $<0.0001$ & & & \\
\hline Stigmatization & $12.81 \pm 19.24$ & $14.14 \pm 21.09$ & 0.069 & & & \\
\hline Social support & $7.29 \pm 15.43$ & $10.01 \pm 19.09$ & $<0.0001$ & & & \\
\hline Cognition & $18.51 \pm 17.38$ & $23.17 \pm 20.16$ & $<0.0001$ & & & \\
\hline Autonomy for ADL & $3.61 \pm 0.86$ & $3.63 \pm 0.88$ & 0.852 & $4.24 \pm 0.75$ & $4.19 \pm 0.61$ & 0.983 \\
\hline Self-esteem & $3.83 \pm 0.76$ & $3.82 \pm 0.81$ & 0.866 & $4.18 \pm 0.68$ & $4.00 \pm 0.66$ & 0.124 \\
\hline Social relationships & $4.04 \pm 0.67$ & $3.94 \pm 0.75$ & 0.004 & $4.29 \pm 0.65$ & $4.19 \pm 0.61$ & 0.071 \\
\hline Economic capacity & $3.84 \pm 0.78$ & $3.77 \pm 0.8$ & 0.091 & $4.07 \pm 0.74$ & $3.97 \pm 0.81$ & 0.078 \\
\hline Habitat & $4.22 \pm 0.67$ & $4.21 \pm 0.67$ & 0.904 & $4.43 \pm 0.63$ & $4.29 \pm 0.66$ & 0.016 \\
\hline
\end{tabular}

$p$-values were computed using the Wilcoxon-signed rank test or marginal homogeneity test. The results represent mean $\pm \mathrm{SD}$ or $\% ; p_{\mathrm{a}}$, V2 vs $\mathrm{V} 0$ in PD patients; $p_{\mathrm{b}}, \mathrm{V} 2$ vs $\mathrm{V} 0$ in controls.

ADLS Schwab \& England Activities of Daily Living Scale, BDI-II Beck Depression Inventory-II, FOGQ Freezing Of Gait Questionnaire, LEDD levodopa equivalent daily dose (mg), NMSS Non-Motor Symptoms Scale, NPI Neuropsychiatric Inventory, PD-CRS Parkinson's Disease Cognitive Rating Scale, PDSS Parkinson's Disease Sleep Scale, QUIP-RS Questionnaire for Impulsive-Compulsive Disorders in Parkinson's Disease-Rating Scale, UPDRS Unified Parkinson's Disease Rating Scale, VAFS Visual Analog Fatigue Scale, VAS-Pain Visual Analog Scale-Pain.

The bold values indicates statistically significant $p$ values.

In the subgroup of early PD $(N=277)$, quite similar results, an increase in mean PDQ-39SI from V0 to V2 of $23.4 \%$ (from $14.22 \pm$ 11.29 to $17.62 \pm 15.36 ; p<0.0001$ ), were observed. Fifty-six patients (20.2\%) presented a clinically significant HRQoL impairment at the 2-year follow-up. However, as in the whole cohort, GQoL did not change significantly (PQ-10, $p=0.111$; EUROHISQOL8, $p=0.756$ ). In the binary regression model, as in the all cohort, to be younger $(\mathrm{OR}=0.813 ; 95 \% \mathrm{Cl} 0.709-0.933 ; p=0.003)$, to be a female $(\mathrm{OR}=35.847 ; 95 \% \mathrm{Cl} 3.452-372.204 ; p=0.003)$, and to have a greater increase in BDI-II $(\mathrm{OR}=1.400 ; 95 \% \mathrm{Cl}$ $1.149-1.705 ; p=0.001)$ and NMSS (OR $=1.069 ; 95 \% \mathrm{Cl}$ $1.007-1.043 ; p=0.001$ ) total scores from V0 to $\mathrm{V} 2$ were associated with clinically significant HRQoL impairment at the 2-year followup, after adjustment to many covariates (Hosmer-Lemeshow test, $p=0.998 ; R^{2}=0.745$ ) (Table 3). When ADLS was included in the model, to be younger ( $\mathrm{OR}=0.769 ; 95 \% \mathrm{Cl} 0.624-0.946 ; p=0.013$ ), 
Table 2. Changes in motor and non-motor symptoms and disability in PD patients from V0 (baseline) to V2 (2 years \pm 1 month) with regards to presenting or not clinically significant $\mathrm{HRQ}$ oL impairment.

\begin{tabular}{|c|c|c|c|}
\hline & $\begin{array}{l}\text { Non clinically } \\
\text { significant HRQoL } \\
\text { impairment } \\
N=407\end{array}$ & $\begin{array}{l}\text { Clinically } \\
\text { significant HRQoL } \\
\text { impairment } \\
N=93\end{array}$ & $p$ \\
\hline Age at baseline & $63.04 \pm 7.99$ & $61.32 \pm 10.17$ & 0.354 \\
\hline Gender (males) (\%) & 60 & 57 & 0.341 \\
\hline $\begin{array}{l}\text { Disease duration } \\
\text { (at V0) }\end{array}$ & $5.65 \pm 4.36$ & $4.91 \pm 3.55$ & 0.247 \\
\hline $\begin{array}{l}\text { Number of non- } \\
\text { antipark. drugs } \\
\text { (at V0) }\end{array}$ & $2.56 \pm 2.36$ & $2.33 \pm 2.49$ & 0.220 \\
\hline \multicolumn{4}{|c|}{ Change at V2 (from Vo to V2) } \\
\hline LEDD & $+177.15 \pm 330.2$ & $+228.75 \pm 318.27$ & 0.174 \\
\hline $\begin{array}{l}\text { Number of non- } \\
\text { antipark. drugs }\end{array}$ & $+0.55 \pm 1.56$ & $+0.65 \pm 1.45$ & 0.685 \\
\hline UPDRS-III (OFF) & $+2.25 \pm 9.77$ & $+7.76 \pm 11.2$ & $<0.0001$ \\
\hline UPDRS-IV & $+0.47 \pm 2.47$ & $+1.47 \pm 2.55$ & 0.002 \\
\hline FOGQ & $+0.68 \pm 3.85$ & $+3.32 \pm 4.71$ & $<0.0001$ \\
\hline PD-CRS & $-2.17 \pm 12.18$ & $-0.67 \pm 10.12$ & 0.293 \\
\hline NMSS & $+4.15 \pm 32.03$ & $+28.64 \pm 35.65$ & $<0.0001$ \\
\hline Cardiovascular & $+6.21 \pm 14.41$ & $+8.11 \pm 12.83$ & 0.310 \\
\hline Sleep/fatigue & $+0.7 \pm 15.96$ & $+12.98 \pm 18.42$ & $<0.0001$ \\
\hline Mood/apathy & $+0.5 \pm 14.57$ & $+8.62 \pm 15.19$ & $<0.0001$ \\
\hline $\begin{array}{l}\text { Perceptual } \\
\text { symptoms }\end{array}$ & $+1.89 \pm 10.61$ & $+4.35 \pm 12.56$ & 0.141 \\
\hline Attention/memory & $+1.74 \pm 14.16$ & $+7.28 \pm 17.30$ & 0.07 \\
\hline $\begin{array}{l}\text { Gastrointestinal } \\
\text { symptoms }\end{array}$ & $+2.19 \pm 12.64$ & $+4.9 \pm 12.8$ & 0.020 \\
\hline Urinary symptoms & $+1.29 \pm 20.22$ & $+9.28 \pm 21.56$ & 0.001 \\
\hline Sexual dysfunction & $+2.63 \pm 30.71$ & $+10.51 \pm 23.43$ & 0.007 \\
\hline Miscellaneous & $+0.72 \pm 14.88$ & $+6.19 \pm 14.89$ & 0.011 \\
\hline BDI-II & $-0.63 \pm 7.75$ & $+4.51 \pm 6.13$ & $<0.0001$ \\
\hline PDSS & $+2.82 \pm 25.80$ & $-9.04 \pm 24.96$ & $<0.0001$ \\
\hline QUIP-RS & $-0.02 \pm 9.25$ & $+0.34 \pm 8.06$ & 0.736 \\
\hline NPI & $-0.43 \pm 4.28$ & $+4.28 \pm 8.06$ & $<0.0001$ \\
\hline VAS-PAIN & $+0.18 \pm 3.21$ & $+1.01 \pm 3.74$ & 0.023 \\
\hline VASF - physical & $+0.09 \pm 2.97$ & $+1.1 \pm 2.92$ & 0.004 \\
\hline VASF-mental & $-0.12 \pm 2.76$ & $+1.05 \pm 2.95$ & 0.002 \\
\hline ADLS & $-2.84 \pm 11.08$ & $-10.97 \pm 12.42$ & $<0.0001$ \\
\hline
\end{tabular}

Chi-squared and Mann-Whitney-Wilcoxon test were applied. The results represent percentages or mean \pm SD. The symbol " + " indicates an increase in the score of the scale at V2 compared to V0 while the symbol "-" indicates a decrease. Data about UPDRS-III are during the OFF state (first hour in the morning without taking medication in the previous $12 \mathrm{~h}$ ).

$A D L S$ Schwab \& England Activities of Daily Living Scale, BDI-II Beck Depression Inventory-II, FOGQ, Freezing of Gait Questionnaire, LEDD levodopa equivalent daily dose (mg), NMSS Non-Motor Symptoms Scale, NPI Neuropsychiatric Inventory, PD-CRS Parkinson's Disease Cognitive Rating Scale, PDSS Parkinson's Disease Sleep Scale, QUIP-RS Questionnaire for Impulsive-Compulsive Disorders in Parkinson's Disease-Rating Scale, UPDRS Unified Parkinson's Disease Rating Scale, VAFS Visual Analog Fatigue Scale, VAS-Pain Visual Analog Scale-Pain.

The bold values indicates statistically significant $p$ values.

to be a female $(\mathrm{OR}=31.982 ; 95 \% \mathrm{Cl} 1.678-609.587 ; \mathrm{p}=0.021)$, and to have a greater increase in BDI-II (OR $=1.197 ; 95 \% \mathrm{Cl}$ $1.126-1.990 ; p=0.006)$, NMSS (Non-Motor Symptoms Scale) $(\mathrm{OR}=1.108 ; 95 \% \mathrm{Cl} 1.033-1.188 ; p=0.004)$ and NPI $(\mathrm{OR}=1.323$;
$95 \% \mathrm{Cl} 1.041-1.681 ; p=0.022)$ total scores from V0 to V2 were associated with clinically significant $\mathrm{HRQoL}$ impairment at the 2-year follow-up (Hosmer-Lemeshow test, $p=0.217 ; R^{2}=0.816$ ), but not the change in the ADLS score (OR $=0.889 ; 95 \% \mathrm{Cl}$ $0.786-1.1006 ; p=0.062$ ). Moderate correlations were observed between the change from V0 to V2 in the PDQ-39SI score and the score in FOGQ $(r=0.39 ; p<0.0001)$, NMSS $(r=0.41 ; p<0.0001)$, NPI $(r=0.35 ; p<0.0001)$ and ADLS $(r=-0.41 ; p<0.0001)$ (Supplementary Table 2).

\section{Predictors of the change in the PDQ-39SI from V0 to V2}

Finally, similar results were observed in both groups, the whole cohort and the early PD subgroup, when a linear regression model was considered (PDQ-39SI change from V0 to V2 as dependent variable) (Supplementary Table 2$)$. To be a female $(\beta=0.17 ; p<$ $0.0001)$ and change in UPDRS-III $(\beta=0.23 ; p<0.0001)$, FOGQ $(\beta=$ $0.20 ; p<0.0001)$, and NMSS $(\beta=0.37 ; p<0.0001)$ scores provided the highest contribution to the model (adjusted R-squared 0.45 ) in the whole cohort. In early PD patients, the variables associated with HRQoL change at the 2-year follow-up were the same (Supplementary Table 2). When the ADLS score was included in the model, the results were similar but with the ADLS as an independent variable associated with HRQoL change too $(\beta=$ $-0.21 ; 95 \% \mathrm{Cl}-0.353,-0.107 ; p<0.0001$; adjusted R-squared 0.45 $[N=500 ;$ all cohort $] ; \beta=-0.23 ; 95 \% \mathrm{Cl}-0.433,-0.076 ; p=0.005$; adjusted R-squared 0.431 [ $N=277$; early PD subgroup]).

\section{DISCUSSION}

In this longitudinal follow-up study, we report that there is a significant HRQoL impairment in PD patients in the short-term and that impairment in the motor status during the OFF state (UPDRS-III), increased gait problems (FOGQ), and increased NMS burden contribute to it. Specifically, mood impairment and NMS burden increase were independent factors associated with clinically significant HRQoL impairment at the 2-year follow-up, which one was present in about every 5 patients. Moreover, the results indicate that it will be especially important to be vigilant about clinically significant $\mathrm{HRQ}$ L impairment in women and younger patients.

After a 2-year follow-up, PD patients from the COPPADIS cohort demonstrated impairment in motor function (H\&Y, UPDRS-III, UPDRSIV, FOGQ). The increase of motor impairments measured with the UPDRS were in agreement with other studies ${ }^{27,28}$. Also, significant changes in NMS were observed in the NMS burden as a whole, pain, fatigue, and cognition, but not in controls. These results aligned with previous longitudinal studies indicating that the severity of NMS in PD tends to become progressively worse with the course of the disease and also indicate that non-motor evaluation is complementary to measuring PD progression ${ }^{19,26,29-32}$. With respect to the QoL, although more than a half of PD patients presented a PDQ-39SI score at the 2-year follow-up higher than at baseline, only $18.6 \%$ presented HRQoL impairment as clinically significant. In a previous study with 707 PD patients followed prospectively for the 2-year as well, $17 \%$ worsened clinically while 584 were rated as stable ${ }^{29}$. The results can be vary due to the definition of QoL impairment as clinically significant ${ }^{31,33,34}$. Based on the postal reply of 728 PD patients, Peto et al. ${ }^{34}$ determined that 1.6 points worsening on a PDQ-39SI is the minimal clinically important difference threshold. More recently, Horváth et al. ${ }^{31}$ considered the most optimal estimates threshold for PDQ-39-SI in +4.22 points for detecting minimal clinically important worsening. However, there is no "gold standard" methodology of estimating the minimal important difference and as the degree of improvement is conditioned by the baseline score; therefore, the use of a percentage might be more appropriate ${ }^{35,36}$. Patients appear to be able to detect changes of $7-10 \%$ on QoL instruments or pain scales $^{36}$. In our case, the minimal important difference was considered 
A

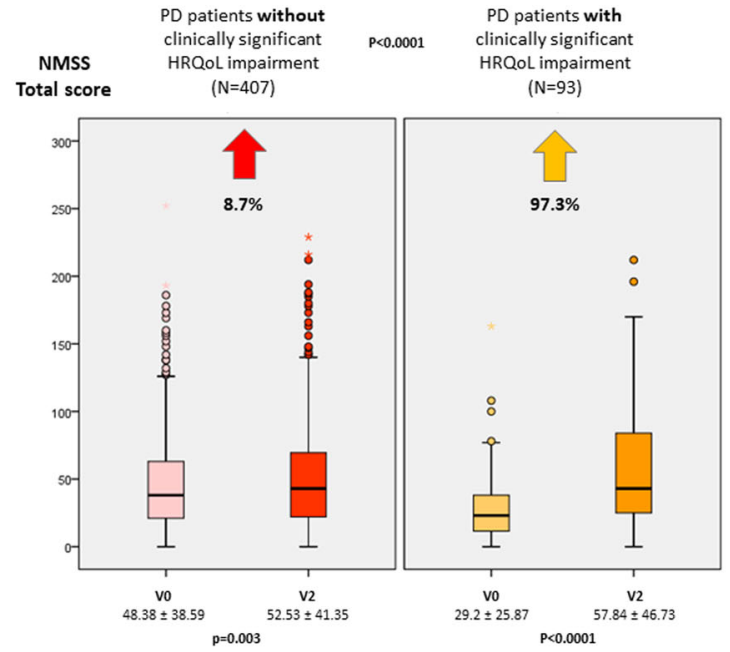

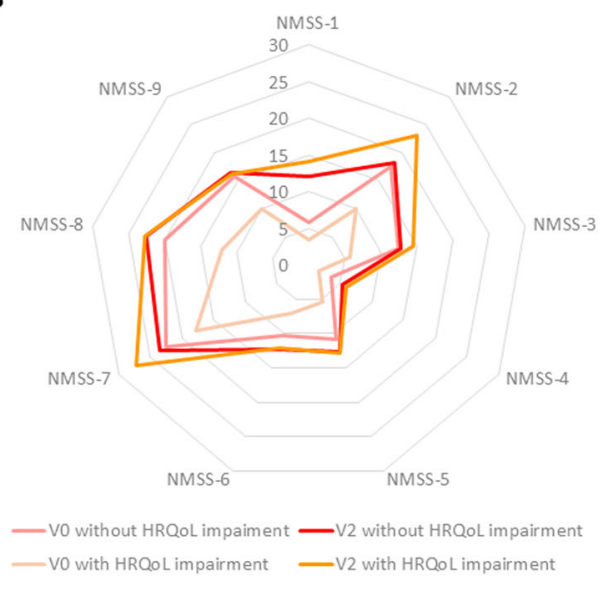

Fig. 2 Evolution of NMS after 2-year follow up. A Change in the NMSS total score from V0 (baseline) to V2 (2 year \pm 1 month) in PD patients without vs with clinically significant HRQoL impairment. B Mean score on each domain of the ESS scale at V0 and V2 in PD patients without vs with clinically significant HRQoL impairment. Data are presented as box plots, with the box representing the median and the two middle quartiles (25-75\%). $p$-values were computed using the Wilcoxon-signed rank test. Mild outliers $(0)$ are data points that are more extreme than Q1 $-1.5 *$ IQR or Q3 + $1.5 *$ IQR. NMSS, Non-Motor Symptoms Scale.

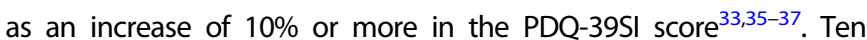
percent of the mean score of the PDQ-39SI in our study represents 1.6 points; therefore, similar to the proposal of Peto et al. ${ }^{34}$. However, in a patient with a higher baseline PDQ-39SI score, for example, 50 points, the minimal clinically significant worsening change should be 5 points. Hence, in less than 1 in 3 patients who had an increase in the PDQ-39 score, this was considered clinically significant. In any case, it seems clear that even in a relatively short follow-up period, patients with PD experience a significant decrease in $\mathrm{HRQOL}^{21,29}$. However, as Reuther et al. ${ }^{22}$ reported in 145 PD patients after a 12month follow-up, there doesn't seem to be a significant change in QoL generic scales.

For assessing the NMS as a whole, we used the NMSS. To date, this scale has been used in more than 100 clinical studies and trials and it has shown to be capable of detecting longitudinal changes in NMS, where studies have shown differential changes over time of several of the NMSS domains ${ }^{32,38,39}$. Moreover, it has been demonstrated a consistent and strong correlations between NMSS burden and HRQoL measures ${ }^{32,40-42}$. In our study, a very clear difference in the change of NMS burden was observed between patients with and without clinically significant HRQoL impairment. Changes in all domains of the NMSS scale correlated with QoL changes. Similarly, previous studies observed a correlation between NMS burden assessed with the NMSS and QoL changes over time ${ }^{19}$. Moreover, in our analysis, NMS burden progression was an independent factor related to HRQoL impairment. Prakash et al. observed for the first time that nonmotor problems provided a better prediction of the change of QoL in 227 PD patients over a 2 -year follow-up period ${ }^{19}$. However, they did not provide the variance value of the model, many factors potentially affecting QoL were not included, and what they considered was the baseline NMSS score. On the contrary, in this study we wanted to analyze in detail what changes in many aspects of the disease observed after the 2-year follow-up contributed to a worsening in the patients' QoL. So, several variables were included, the results of the model represented $\sim 70 \%$ of the variance when HRQoL changes were considered, and the changes in all variables were adjusted to the scores at baseline. To our best knowledge, this is the first longitudinalprospective study analyzing in such detail which are the predictors of QoL impairment in a large sample of PD patients. Reinforcing the idea that the progression of NMS is pivotal to the worsening of the QoL throughout the evolution of the disease, improvements of
NMS were associated with improved QoL in advanced parkinsonian patients during 2-year treatment with levodopa-carbidopa intestinal gel infusion therapy ${ }^{43}$. In line with this, Erro et al. observed that NMS significantly affected QoL in PD, demonstrating that this was especially the case when patients were in their honeymoon period (during which time the side effects of the disease aren't too disabling and there is a response to medications $)^{44}$. In the subgroup of early PD patients from our study, the change in the NMSS total score at 2-years was one of the most significant contributors to HRQoL impairment.

Another important factor is mood. Like in other studies, the mean score of BDI didn't change over time ${ }^{18,22}$, suggesting that depression-type frequency does not appear to change over time in $\mathrm{PD}^{45}$. Cross-sectional studies have reported the clear contribution of depression or a worse mood to a poorer QoL in PD patients ${ }^{3,12,13}$. In fact, it was observed in the COPPADIS baseline cross-sectional analysis ${ }^{14}$. However, to our knowledge, this is the first time that mood worsening is identified as an independent factor associated with clinically significant HRQoL impairment in PD patients. This subgroup of patients $(\mathrm{N}=93)$ presented a mean increase in the BDI-II score of 4.5 points at the 2-year follow-up and specifically, an increase in $\geq 5$ points multiplied by 5 the probability of presenting a clinically significant HRQoL impairment, independent of other factors. Reuther et al. ${ }^{22}$ identified depression as the strongest predictor for reduced HRQoL in 145 PD patients after 1-year follow-up. However, we identified the change in the score of the BDI-II as a predictor of clinically significant HRQoL impairment after adjustment to BDI-II score at baseline. From a practical point of view, our findings suggest an important role of the neurologist being alert to a possible worsening of mood, as well as greater NMS burden, in patients with PD throughout the evolution of the disease since this is what impacts on the patient's QoL. Knowing what impacts on the QoL and contributes to its worsening, depending on the variable, intervention measures with the intention of correcting them can be proposed ${ }^{46}$. Studies demonstrating a QoL improvement correlated with mood and NMS burden improvement have been published ${ }^{47}$. With regards of the results observed here, it should be necessary to be alert about mood and NMS burden changes over time, especially in younger patients and females. A mildly significant gender difference in disability and QoL reporting has been noted, with women citing greater disability and reduced $\mathrm{QoL}^{48,49}$. Depression and fatigue were the major causes of low 
Table 3. Binary logistic regression model about factors associated with clinically significant HRQoL impairment at V2 (2 years follow-up).

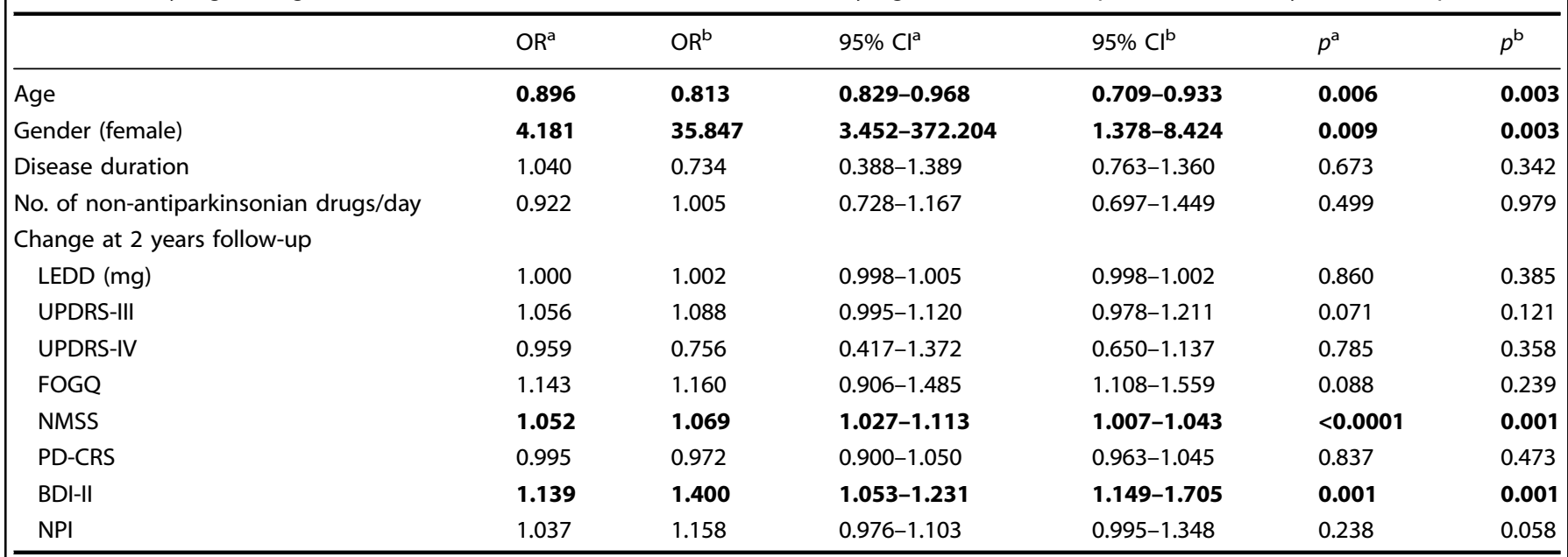

Dependent variable: Clinically significant HRQoL impairment (defined as PDQ-39SI $\mathrm{V}_{2} \geq 10 \% \mathrm{PDQ}-39 \mathrm{SI} \mathrm{V}_{\mathrm{VO}}$ ). OR and 95\% $\mathrm{Cl}$ are shown. Hosmer-Lemeshow test, $p_{\mathrm{a}}=0.665 ; p_{\mathrm{b}}=0.998 ; R_{\mathrm{a}}^{2}=0.655 ; R^{2} \mathrm{~b}=745$. The model was adjusted to variables at baseline: LEDD (mg), UPDRS-III, UPDRS-IV, FOGQ, NMSS, PD-CRS, BDI-II, $\mathrm{NPI}, \mathrm{PDQ}-39 \mathrm{SI}$.

BDI-II Beck Depression Inventory-II, FOGQ Freezing Of Gait Questionnaire, LEDD levodopa equivalent daily dose (mg), NMSS Non-Motor Symptoms Scale, NPI Neuropsychiatric Inventory, PD-CRS Parkinson's Disease Cognitive Rating Scale, PDQ-39SI 39-item Parkinson's Disease Quality of Life Questionnaire Summary Index, QUIP-RS, Questionnaire for Impulsive-Compulsive Disorders in Parkinson's Disease-Rating Scale, UPDRS Unified Parkinson's Disease Rating Scale.

${ }^{\text {aAll }}$ cohort $(n=500)$.

bEarly PD patients $(n=277)$.

The bold values indicates statistically significant $p$ values.

HRQoL in women even in the early phases of $P D^{50}$. To attenuate this sex difference in disease experience, psychological distress screening and management (particularly targeting females) should be considered as part of PD clinical care ${ }^{23}$. Moreover, QoL, as measured on the PDQ-39, is significantly worse in youngonset PD patients than in older-onset PD patients, and youngonset PD patients also experience loss of employment, disruption of family life, greater perceived stigmatization, and depression than do older-onset PD patients ${ }^{51,52}$.

The most important limitation of this study is the fact that information about follow-up was recorded only in 524 patients of 695 initially included in the study (75.5\%). Of them, data for the PDQ-39, PQ-10, and EUROHIS-QOL8 at baseline and at V2 was available in 500, 503, and 507 PD patients, respectively. Thirty-eight patients (5.5\%) dropped out of the study (1 death; 2 with change in diagnosis; 35 other reasons) at the 2-year follow-up and 132 (19\%) were not assessed. However, this is a limitation observed in other prospective studies. Of 7507 PD patients, follow-up data was available only for 4680 participants $(62.3 \%)^{53}$. In the study of Antonini et al. ${ }^{29}, 707$ PD patients from 1142 initially included (61.9\%) were evaluable at 24 months. An important second limitation is that PD patients older than 75 years old were excluded from participation by COPPADIS study protocol ${ }^{14}$, which leads to an early PD bias in this cohort. For some variables, the information was not collected in all cases. Moreover, this is a multicenter mono-country study, being the ideal for this type of studies the participation of patients from different parts of the world, so the results should be considered with caution when extrapolating them to the general PD population (i.e., race, country healthcare, etc.). By the contrary, strengths of our study include a very complete assessment, the large sample size, a prospective longitudinal follow-up design, the fact that this analysis was "a priori" planned as one objective of the multicenter COPPADIS project ${ }^{16}$, and the extensive clinical and demographic information recorded.

The findings of this study have important implications in daily clinical practice. In a disorder like PD in which one there is no a cure, treatment is symptomatic and the aim is to improve the patient's QoL. This is complex because many factors influence
QoL in PD. Furthermore, PD is a complex disorder with many manifestations and with a great variability in its progression among patients. Regarding this study observations, some important points should be considered in daily clinical practice. First, a complete assessment of the patient with PD periodically including motor status, NMS, QoL and disability should be the ideal practice. Second, NMS progression contributes significantly to a QoL worsening and it is crucial its evaluation. Very interestingly, we reported very recently that PD patients from the COPPADIS cohort with a lower H\&Y stage but a greater global NMS burden may have a worse QoL than patients with a higher $\mathrm{H} \& Y$ stage but lower global NMS ${ }^{54}$. Third, mood is another key factor to consider whenever we evaluate the patient in clinical practice. Fourth, we have to keep in mind that mood impairment and global NMS progression predict a patient's QoL worsening. Finally, we should be especially careful in all of the above in the case of a female patient and in young patients.

A problem in clinical practice is the lack of time to evaluate the patient. For the PD patient, to bring adequately covered questionnaires to the consultation, for example with the help of nursing staff, or even in the future with mobile applications that transfer the data to the patient's medical record, it could be a possibility that facilitates the complete and comprehensive assessment. In general, it is something that is not done today, and proof of this is the alarming lack of literature about the global progression of the disease including NMS in large cohorts of patients. More studies with large PD cohorts and long-term follow-up are required. Our aim with the COPPADIS cohort is to follow for 5 years ${ }^{55}$. Collecting data from different cohorts and making comparisons would also be of great interest.

In conclusion, the present study observes HRQoL impairment in PD patients in a short 2-year follow-up, even in early PD patients, but not the GQoL. A younger age, to be a female, and mood and NMS burden impairment were associated with clinically significant $\mathrm{HRQ}$ L impairment after the 2-year followup. The progression of NMS is pivotal in the worsening of the QoL throughout the evolution of the disease in PD, and it is necessary to keep in mind to ask for mood or NMS changes, especially in females and young patients. 


\section{METHODS}

PD patients and controls who were recruited from January 2016 to November 2017 (baseline visit; V0) and evaluated again at the 2-year follow-up (V2) from 35 centers of Spain from the COPPADIS cohort ${ }^{56}$, were included in the study. Methodology about COPPADIS-2015 has been previously published ${ }^{57}$. This is a multicenter, observational, longitudinalprospective, 5-year follow-up study designed for analyzing disease progression in a Spanish population of PD patients. Specifically, 17 objectives were proposed in the protocol ${ }^{55}$. Even though the recruitment period ended in October 2017, the prospective follow-up phase is ongoing. Patients, caregivers (patient's primary caregiver), and controls (subjects without PD and any other severe and disabling concomitant disorder) were included $^{55}$. Annual visits from V0 (baseline) to V5 (60 moths \pm 3 months) are conducted to the patients and at V0, V2, V4, and V5 to the controls and caregivers. All patients included were diagnosed according to UK PD Brain Bank criteria ${ }^{57}$. Exclusion criteria ${ }^{55}$ were: non-PD parkinsonism, dementia criteria (Mini Mental State Examination [MMSE] $\geq 26$ ), age $<18$ or $>75$ years, inability to read or understand the questionnaires, to be receiving any advanced therapy (continuous infusion of levodopa or apomorphine, and/ or with deep brain stimulation), and presence of comorbidity, sequelae, or any disorder that could interfere with the assessment.

Information on sociodemographic aspects, factors related to $P D$, comorbidity, and treatment were collected. V0 and V2 evaluations included ${ }^{55}$ : (1) motor assessment (Hoenh \& Yahr $[\mathrm{H} \& \mathrm{Y}]^{58}$, Unified Parkinson's Disease Rating Scale [UPDRS] part III and part IV ${ }^{59}$, Freezing of Gait Questionnaire [FOGQ] ${ }^{60}$; (2) NMS (Non-Motor Symptoms Scale $\left[\right.$ NMSS] ${ }^{61}$, Parkinson's Disease Sleep Scale [PDSS] ${ }^{62}$, Visual Analog ScalePain [VAS-Pain] ${ }^{63}$, Visual Analog Fatigue Scale [VAFS] ${ }^{64}$, cognition (MMSE ${ }^{65}$, Parkinson's Disease Cognitive Rating Scale [PD-CRS] ${ }^{66}$, completing a simple 16-piece puzzle); (3) mood and neuropsychiatric symptoms (Beck Depression Inventory-II $[\mathrm{BDI}-1 \mathrm{II}]^{67}$, Neuropsychiatric Inventory $[\mathrm{NPI}]^{68}$, Questionnaire for Impulsive-Compulsive Disorders in Parkinson's DiseaseRating Scale [QUIP-RS] ${ }^{69}$; (4) and disability (Schwab \& England Activities of Daily Living Scale $[A D L S]^{70}$. In patients with motor fluctuations, the motor assessment was made during the OFF state (without medication in the last $12 \mathrm{~h}$ ) and during the ON state. On the other hand, the assessment was only conducted without medication in patients without motor fluctuations. The same evaluation as for the patients, except for the motor assessment, was conducted in control subjects at V0 and at V2 (2 years \pm 1 month). Three scales were used to assess QoL at $\mathrm{V} 0$ and at $\mathrm{V}^{28}$ : (1) the 39-item Parkinson's disease Questionnaire $(\mathrm{PDQ}-39)^{71},(2)$ a rating of global perceived QoL (PQ-10) on a scale from 0 (worst) to 10 (best) ${ }^{13}$, and (3) the EUROHIS-QOL 8-item index (EUROHIS-QOL8) ${ }^{72}$. The PDQ-39 is a PDspecific questionnaire that assesses the patients' HRQoL. There are 39 items grouped into 8 domains: (1) Mobility (items 1 to 10); (2) Activities of daily living (items 11 to 16); (3) Emotional well-being (items 17 to 22); (4) Stigma (items 23 to 26); (5) Social support (items 27 to 29); (6) Cognition (items 30 to 33); (7) Communication (items 34 to 36); (8) Pain and discomfort (items 37 to 39). For each item, the score may range from 0 (never) to 4 (always). The symptoms refer to the 4 weeks prior to assessment. Domain total scores are expressed as a percentage of the corresponding maximum possible score and a Summary Index is obtained as average of the domain scores. The EUROHIS-QOL8 is an 8-item GQoL questionnaire (quality of life, health status, energy, autonomy for activities of daily living, self-esteem, social relationships, economic capacity, and habitat) derived from the WHOQOL-BREF. For each item, the score ranges from 0 (not at all) to 5 (completely). The total score is expressed as the mean of the individual scores. A higher score indicates a better QoL. In controls, only the PQ-10 and the EUROHIS-QOL8 were assessed.

Clinically significant $\mathrm{HRQ}$ oL impairment was defined as presenting an increase in PDQ-39SI score at V2 $\geq 10 \%$ of score at baseline (V0) whereas GQoL impairment as presenting a decrement in PQ-10 and/or EUROHISQOL8 score at V2 $\leq 10 \%$ of score at baseline (V0) ${ }^{33}$. Taking into account that in the COPPADIS cohort the range of disease duration varies from $<1$ year to 30 years and based on the general response to treatment and progression of symptoms in PD and considering a recent publication of this same cohort ${ }^{73}$, patients with $\leq 5$ years of disease duration were considered as early PD patients.

\section{Data analysis}

Data were processed using SPSS 20.0 for Windows. For comparisons between patients and controls, the Student's $t$-test, Mann-Whitney $U$ test, Chi-square test, or Fisher test were used as appropriate (distribution for variables was verified by one-sample Kolmogorov-Smirnov test). The Wilcoxon-signed rank test was performed to test whether the mean differences of the PDQ-39SI, PQ-10, and EUROHIS-QOL8 scores and the individual PDQ-39SI and EUROHIS$\mathrm{QOL} 8$ domain scores between the two visits (V0 and V2) were significant. This test and/or the marginal homogeneity test were applied for other scales for analyzing the change from V0 to V2. Spearman's or Pearson's correlation coefficient, as appropriate, were used for analyzing the relationship between continuous variables. Correlations were considered weak for coefficient values $\leq 0.29$, moderate for values between 0.30 and 0.59 , and strong for values $\geq 0.60$.

Clinically significant QoL impairment was expressed as a percentage and it was only calculated if the change between scores (PDQ-39SI; PQ-10; EUROHIS-QOL8) from V0 to V2 was significant. For determining predictive factors of QoL impairment, a logistic regression model (QoL impairment as dependent variable) was performed. The model was well-planned, as recommended by best-practice methods ${ }^{74}$, in which known and presumably predictor variables affecting QoL changes (dependent variable) were included: change from $\mathrm{V} 0$ to $\mathrm{V} 2$ in levodopa equivalent daily dose $\left(\right.$ LEDD) ${ }^{75}$, UPDRS-III-OFF (motor severity), UPDRS-IV (motor complications), FOGQ, NMSS (NMS burden), PD-CRS (cognition), BDI-II (mood), and NPI (neuropsychiatric symptoms). The model was adjusted to baseline QoL and age, gender, disease duration, comorbidity (total number of nonantiparkinsonian medications as surrogate marker $\left.{ }^{14}\right)$, and the score of the rest of the variables at baseline (LEDD, UPDRS-III-OFF, UPDRS-IV, FOGQ, NMSS, PD-CRS, and NPI). Disability (ADLS) was not included in the model because this is consequence of symptoms, but since it is related to QoL, in a second model ADLS at baseline and change in ADLS from V0 to V2 were included. Hosmer-Lemeshow test was applied and adjusted R-squared was calculated for all analyses. Finally, multiple linear regressions were performed with "change in QoL" as dependent variable but only for variables (PDQ-39SI; PQ-10; EUROHIS-QOL8) changing significantly from V0 to $\mathrm{V} 2$. The independent variables included were the same as in the binary model. The $p$-value was considered significant when it was $<0.05$.

\section{Standard protocol approvals, registrations, and patient consents}

The Comité de Ética de la Investigación Clínica de Galicia from Spain (2014/ $534 ; 02 / D E C / 2014$ ) approval was obtained. Written informed consents from all participants in this study were obtained before the start of the study. COPPADIS-2015 was classified by the AEMPS as a Post-authorization Prospective Follow-up study with the code COH-PAK-2014-01.

\section{Reporting summary}

Further information on research design is available in the Nature Research Reporting Summary linked to this article.

\section{DATA AVAILABILITY}

The data that support the findings of this study are available from the corresponding author upon reasonable request.

\section{CODE AVAILABILITY}

No computer coding was used in the completion of the current manuscript.

Received: 25 March 2021; Accepted: 27 July 2021; Published online: 16 December 2021

\section{REFERENCES}

1. Chaudhuri, K. R. et al. The nondeclaration of nonmotor symptoms of Parkinson's disease to health care professionals: an international study using the nonmotor symptoms questionnaire. Mov. Disord. 25, 704-709 (2010).

2. Hinnell, C. et al. Nonmotor versus motor symptoms: how much do they matter to health status in Parkinson's disease? Mov. Disord. 27, 236-241 (2012).

3. Schrag, A., Jahanshahi, M. \& Quinn, N. What contributes to quality of life in patients with Parkinson's disease? J. Neurol. Neurosurg. Psychiatry 69, 308-312 (2000).

4. Kuopio, A. M., Marttila, R. J., Helenius, H., Toivonen, M. \& Rinne, U. K. The quality of life in Parkinson's disease. Mov. Disord. 15, 216-223 (2000).

5. Muslimovic, D., Post, B., Speelman, J. D., Schmand, B. \& de Haan, R. J. Determinants of disability and quality of life in mild to moderate Parkinson disease. Neurology 70, 2241-2247 (2008). 
6. Behari, M., Srivastava, A. K. \& Pandey, R. M. Quality of life in patients with Parkinson's disease. Parkinsonism Relat. Disord. 11, 221-226 (2005).

7. Karlsen, K. H., Larsen, J. P., Tandberg, E. \& Maland, J. G. Quality of life measurements in patients with Parkinson's disease: a communitybased study. Eur. J. Neurol. 5, 443-450 (1998).

8. Rahman, S., Griffin, H. J., Quinn, N. P. \& Jahanshahi, M. Quality of life in Parkinson's disease: the relative importance of the symptoms. Mov. Disord. 23, 1428-1434 (2008).

9. Slawek, J., Derejko, M. \& Lass, P. Factors affecting the quality of life of patients with idiopathic Parkinson's disease-a cross-sectional study in an outpatient clinic attendees. Parkinsonism Relat. Disord. 11, 465-468 (2005).

10. Chapuis, S., Ouchchane, L., Metz, O., Gerbaud, L. \& Durif, F. Impact of the motor complications of Parkinson's disease on the quality of life. Mov. Disord. 20, 224-230 (2005).

11. Karlsen, K. H., Larsen, J. P., Tandberg, E. \& Maeland, J. G. Influence of clinical and demographic variables on quality of life in patients with Parkinson's disease. J. Neurol. Neurosurg. Psychiatry 66, 431-435 (1999).

12. Martinez-Martin, P. et al. The impact of non-motor symptoms on health-related quality of life of patients with Parkinson's disease. Mov. Disord. 26, 399-406 (2011).

13. Santos García, D. \& de la Fuente-Fernández, R. Impact of non-motor symptoms on health-related and perceived quality of life in Parkinson's disease. J. Neurol. Sci. 332, 136-140 (2013).

14. Santos García, D. et al. Non-motor symptoms burden, mood, and gait problems are the most significant factors contributing to a poor quality of life in nondemented Parkinson's disease patients: results from the COPPADIS Study Cohort. Parkinsonism Relat. Disord. 66, 151-157 (2019).

15. Martinez-Martin, P. What is quality of life and how do we measure it? Relevance to Parkinson's disease and movement disorders. Mov. Disord. 32, 382-392 (2017)

16. Martinez-Martin, P. \& Kurtis, M. M. Health-related quality of life as an outcome variable in Parkinson's disease. Ther. Adv. Neurol. Disord. 5, 105-117 (2012).

17. Soh, S. E., Morris, M. E. \& McGinley, J. L. Determinants of health-related quality of life in Parkinson's disease: a systematic review. Parkinsonism Relat. Disord. 17, 1-9 (2011).

18. Karlsen, K. H., Tandberg, E., Arsland, D. \& Larsen, J. P. Health related quality of life in Parkinson's disease: a prospective longitudinal study. J. Neurol. Neurosurg. Psychiatry 69, 584-589 (2000).

19. Prakash, K. M., Nadkarni, N. V., Lye, W. K., Yong, M. H. \& Tan, E. K. The impact of non-motor symptoms on the quality of life of Parkinson's disease patients: a longitudinal study. Eur. J. Neurol. 23, 854-860 (2016).

20. Higginson, I. J. et al. Symptoms and quality of life in late stage Parkinson syndromes: a longitudinal community study of predictive factors. PLOS ONE 7, e46327 (2012)

21. Visser, M., Verbaan, D., van Rooden, S., Marinus, J., van Hilten, J. \& Stiggelbout, A. A longitudinal evaluation of health-related quality of life of patients with Parkinson's disease. Value Health 12, 392-396 (2009).

22. Reuther, M. et al. Assessing health-related quality of life in patients with Parkinson's disease in a prospective longitudinal study. Parkinsonism Relat. Disord. 13, 108-114 (2007).

23. Abraham, D. S. et al. Sex differences in Parkinson's disease presentation and progression. Parkinsonism Relat. Disord. 69, 48-54 (2019).

24. Klietz, M. et al. Impaired quality of life and need for palliative care in a German Cohort of advanced Parkinson's disease patients. Front. Neurol. 9, 120 (2018)

25. Fasano, A. et al. Characterizing advanced Parkinson's disease: OBSERVE-PD observational study results of 2615 patients. BMC Neurol. 19, 50 (2019).

26. Valkovic, P., Harsany, J., Hanakova, M., Martinkova, J. \& Benetin, J. Nonmotor symptoms in early- and advanced-stage Parkinson's disease patients on dopaminergic therapy: how do they correlate with quality of life? ISRN Neurol. 2014, 587302 (2014).

27. Velseboer, D. C. et al. Prognostic factors of motor impairment, disability, and quality of life in newly diagnosed PD. Neurology 80, 627-633 (2013).

28. Post, B. et al. Progression and prognostic factors of motor impairment, disability and quality of life in newly diagnosed Parkinson's disease. Mov Disord. 26, 449-456 (2011).

29. Antonini, A. et al. The progression of non-motor symptoms in Parkinson's disease and their contribution to motor disability and quality of life. J. Neurol. 259, 2621-2631 (2012)

30. Simuni, T. et al. Baseline prevalence and longitudinal evolution of non-motor symptoms in early Parkinson's disease: the PPMI cohort. J. Neurol. Neurosurg. Psychiatry. 89, 78-88 (2018).

31. Horváth, K. et al. Changes in quality of life in Parkinson's disease: how large must they be to be relevant? Neuroepidemiology 48, 1-8 (2017).

32. Ou, R. et al. Progression of non-motor symptoms in Parkinson's disease among different age populations: a two-year follow-up study. J. Neurol. Sci. 360, $72-77$ (2016).

33. Ringash, J., O'Sullivan, B., Bezjak, A. \& Redelmeier, D. A. Interpreting clinically significant changes in patient-reported outcomes. Cancer 110, 196-202 (2007).
34. Peto, V., Jenkinson, C. \& Fitzpatrick, R. Determining minimally important differences for the PDQ-39 Parkinson's disease questionnaire. Age Ageing 30, 299-302 (2001).

35. Brozek, J. L., Guyatt, G. H. \& Schünemann, H. J. How a well-grounded minimal important difference can enhance transparency of labelling claims and improve interpretation of a patient reported outcome measure. Health Qual. Life Outcomes 27, 69 (2006).

36. Barrett, B., Brown, D., Mundt, M. \& Brown, R. Sufficiently important difference: expanding the framework of clinical significance. Med. Decis. Making 25, 250-261 (2005).

37. Deng, X. et al. Four-year longitudinal study of motor and non-motor symptoms in LRRK2-related Parkinson's disease. Front. Neurol. 10, 1379 (2020).

38. van Wamelen, D. J. et al. International Parkinson and Movement Disorder Society Parkinson's Disease Non-Motor Study Group. The Non-Motor Symptoms Scale in Parkinson's disease: validation and use. Acta Neurol. Scand. 143, 3-12 (2021)

39. Martinez-Martin, P. et al. Gender-related differences in the burden of non-motor symptoms in Parkinson's disease. J. Neurol. 259, 1639-1647 (2012).

40. Guo, X. et al. Disease duration-related differences in non-motor symptoms: a study of 616 Chinese Parkinson's disease patients. J. Neurol. Sci. 330, 32-37 (2013).

41. Song, W. et al. The impact of non-motor symptoms on the health-related quality of life of Parkinson's disease patients from Southwest China. Parkinsonism Relat. Disord. 20, 149-152 (2014).

42. Wu, Y. et al. Determinants of the quality of life in Parkinson's disease: results of a cohort study from Southwest China. J. Neurol. Sci. 340, 144-149 (2014).

43. Ray Chaudhuri, K. et al. Burden of non-motor symptoms in Parkinson's disease patients predicts improvement in quality of life during treatment with levodopacarbidopa intestinal gel. Eur. J. Neurol. 26, 581-e43 (2019).

44. Erro, R. et al. The non-motor side of the honeymoon period of Parkinson's disease and its relationship with quality of life: a 4-year longitudinal study. Eur. J. Neurol. 23, 1673-1679 (2016).

45. Santos-García, D. et al. Sleep problems are related to a worse quality of life and a greater non-motor symptoms burden in Parkinson's disease. Int. J. Geriatr. Psychiatry 34, 642-658 (2021).

46. Rafferty, M. R. et al. Regular exercise, quality of life, and mobility in Parkinson's disease: a longitudinal analysis of National Parkinson Foundation quality improvement initiative data. J. Parkinsons. Dis. 7, 193-202 (2017).

47. Santos García, D. et al. Safinamide improves non-motor symptoms burden in Parkinson's disease: an open-label prospective study. Brain Sci. 11, 316 (2021).

48. Shulman, L. M. Gender differences in Parkinson's disease. Gend. Med. 4, 8-18 (2007).

49. Crispino, P. et al. Gender differences and quality of life in Parkinson's disease. Int. J. Environ. Res. Public. Health 18, 198 (2020).

50. Yoon, J. E. et al. Gender differences of nonmotor symptoms affecting quality of life in Parkinson disease. Neurodegener. Dis. 17, 276-280 (2017).

51. Schrag, A., Hovris, A., Morley, A., Quinn, A. \& Jahanshahi, M. Young- versus olderonset Parkinson's disease: impact of disease and psychosocial consequences. Mov. Disord. 18, 1250-1256 (2003).

52. Mehanna, R. \& Jankovic, J. Young-onset Parkinson's disease: Its unique features and their impact on quality of life. Parkinsonism Relat. Disord. 65, 39-48 (2019).

53. Shahgholi, L. et al. Hospitalization and rehospitalization in Parkinson disease patients: data from the National Parkinson Foundation Centers of Excellence. PLOS ONE 12, e0180425 (2017).

54. Santos García, D. et al. Staging Parkinsonas disease combining motor and nonmotor symptoms correlates with disability and quality of life. Parkinsons Dis. 2021, 8871549 (2021).

55. Santos-García, D. et al. COPPADIS Study Group. COPPADIS-2015 (COhort of Patients with PArkinson's Dlsease in Spain, 2015), a global-clinical evaluations, serum biomarkers, genetic studies and neuroimaging-prospective, multicenter, non-interventional, long-term study on Parkinson's disease progression. BMC Neurol. 16, 26 (2016).

56. Santos García, D. et al. COPPADIS Study Group. COPPADIS-2015 (COhort of Patients with PArkinson's Dlsease in Spain, 2015): an ongoing global Parkinson's disease project about disease progression with more than 1000 subjects included. Results from the baseline evaluation. Eur. J. Neurol. 26, 1399-1407 (2019).

57. Daniel, S. E. \& Lees, A. J. Parkinson's Disease Society Brain Bank, London: overview and research. J. Neural. Transm. Suppl. 39, 165-172 (1993).

58. Hoehn, M. M. \& Yahr, M. D. Parkinsonism: onset, progression and mortality. Neurology 17, 427-442 (1967).

59. Fanhn, S., Elton, R. L. \& Members of the UPDRS Development Committee. in Recent Developments in Parkinson's Disease (eds. Fahn, S., Marsden, C. D., Calne, D. B. \& Goldstein M.) Vol. 2, 153-164 (Macmillan Health Care Information, Florham Park, NJ, 1987).

60. Giladi, N., Shabtai, H., Simon, E. S., Biran, S., Tal, J. \& Korczyn, A. D. Construction of freezing of gait questionnaire for patients with Parkinsonism. Parkinsonism Relat. Disord. 6, 165-170 (2000). 
61. Chaudhuri, K. R. et al. The metric properties of a novel non-motor symptoms scale for Parkinson's disease: Results from an international pilot study. Mov. Disord. 22, 1901-1911 (2007).

62. Chaudhuri, K. R. et al. The Parkinson's disease sleep scale: a new instrument for assessing sleep and nocturnal disability in Parkinson's disease. J. Neurol. Neurosurg. Psychiatry 73, 629-635 (2002).

63. Burckhardt, C. S. \& Jones, K. D. Adult measures of pain: The McGill Pain Questionnaire (MPQ), Rheumatoid Arthritis Pain Scale (RAPS), Short Form McGill Pain Questionnaire (SF-MPQ), Verbal Descriptive Scale (VDS), Visual Analog Scale (VAS), and West Haven-Yale Multidisciplinary Pain Inventory (WHYMPI). Arthritis. Rheum. 49, 96-104 (2003).

64. Tseng, B. Y., Gajewski, B. J. \& Kluding, P. M. Reliability, responsiveness, and validity of the visual analog fatigue scale to measure exertion fatigue in people with chronic stroke: a preliminary study. Stroke. Res. Treat. 2010, 412964 (2010).

65. Folstein, M. F., Folstein, S. E. \& McHugh, P. R. Mini-mental state". A practical method for grading the cognitive state of patients for the clinician. J. Psychiatr. Res. 12, 189-198 (1975).

66. Pagonabarraga, J., Kulisevsky, J., Llebaria, G., García-Sánchez, C., Pascual-Sedano, B. \& Gironell, A. Parkinson's disease-cognitive rating scale: a new cognitive scale specific for Parkinson's disease. Mov. Disord. 23, 998-1005 (2008).

67. Beck, A. T., Steer, R. A. \& Brown, G. K. Beck Depression Inventory 2nd ed (The Psychological Corporation, San Antonio, 1996).

68. Cummings, J. L., Mega, M., Gray, K., Rosenberg-Thompson, S., Carusi, D. A. \& Gornbein, J. The Neuropsychiatric Inventory: comprehensive assessment of psychopathology in dementia. Neurology 44, 2308-2314 (1994).

69. Weintraub, D. et al. Validation of the questionnaire for impulsive-compulsive disorders in Parkinson's disease. Mov. Disord. 24, 1461-1467 (2009).

70. Schwab, R. S. \& England, A. C. In Third Symposium on Parkinson's Disease 152-157 (E. And S. Livingstone, Edinburgh, 1969).

71. Jenkinson, C., Fitzpatrick, R., Peto, V., Greenhall, R. \& Hyman, N. The Parkinson's Disease Questionnaire (PDQ-39): development and validation of a Parkinson's disease summary index score. Age Ageing 26, 353-357 (1997).

72. Da Rocha, N. S., Power, M. J., Bushnell, D. M. \& Fleck, M. P. The EUROHIS-QOL 8-item index: comparative psychometric properties to its parent WHOQOL-BREF. Value Health 15, 449-457 (2012).

73. Santos-García, D. et al. COPPADIS Study Group. Non-motor symptom burden is strongly correlated to motor complications in patients with Parkinson's disease. Eur. J. Neurol. 27, 1210-1223 (2020).

74. Cohen, J. \& Cohen, P. Applied Multiple Regression/Correlation Analysis for the Behavioral Sciences 2nd ed (Lawrence Erlbaum, Hillsdale, New Jersey, 1983).

75. Schade, S., Mollenhauer, B. \& Trenkwalder, C. Levodopa equivalent dose conversion factors: an updated proposal including opicapone and safinamide. Mov. Disord. Clin. Pract. 2020, 343-345 (2020)

\section{ACKNOWLEDGEMENTS}

We would like to thank all patients and their caregivers who collaborated in this study. Many thanks also to Fundación Española de Ayuda a la Investigación en Parkinson y otras Enfermedades Neurodegenerativas (Curemos el Parkinson; www. curemoselparkinson.org), Alpha Bioresearch (www.alphabioresearch.com), and other institutions helping us.

\section{AUTHOR CONTRIBUTIONS}

S.G.D.: conception, organization, and execution of the project; statistical analysis; writing of the first draft of the manuscript; recruitment and/or evaluation of participants. D.D.T.: review and critique; recruitment and/or evaluation of participants. C.C.: review and critique. M.G.: review and critique. P.G.J.M.: review and critique. M.M. C.: review and critique. S.E.: review and critique; recruitment and/or evaluation of participants. J.S.: review and critique; recruitment and/or evaluation of participants. A.M.: review and critique; recruitment and/or evaluation of participants. P.P.: review and critique; recruitment and/or evaluation of participants. P.L.L.: review and critique; recruitment and/or evaluation of participants. C.M.: review and critique; recruitment and/or evaluation of participants. G.C.J.: review and critique; recruitment and/or evaluation of participants. C.N.: review and critique; recruitment and/or evaluation of participants. L.I.: review and critique; recruitment and/or evaluation of participants. H.V.J.: review and critique; recruitment and/or evaluation of participants. C.I.: review and critique; recruitment and/or evaluation of participants. L.M.L.: review and critique; recruitment and/or evaluation of participants. G.A.I.: review and critique; recruitment and/or evaluation of participants. Á.R.M.A.: review and critique; recruitment and/or evaluation of participants. C.M.J.: review and critique; recruitment and/or evaluation of participants. N.V.: review and critique; recruitment and/or evaluation of participants. P.V.: review and critique; recruitment and/or evaluation of participants. R.d.A.M.: review and critique; recruitment and/or evaluation of participants. B.C.: review and critique; recruitment and/or evaluation of participants. S.V.B.: review and critique; recruitment and/or evaluation of participants. Á.S.M.: review and critique; recruitment and/or evaluation of participants. V.L.: review and critique; recruitment and/or evaluation of participants. E.S.: review and critique; recruitment and/or evaluation of participants. C.E.: review and critique; recruitment and/or evaluation of participants. C.P.F.: review and critique; recruitment and/or evaluation of participants. M.C.J.C.: review and critique; recruitment and/or evaluation of participants. S.A.P.: review and critique; recruitment and/or evaluation of participants. A.L.M.G.: review and critique; recruitment and/or evaluation of participants. L.A.N.: review and critique; recruitment and/or evaluation of participants. G.l.: review and critique; recruitment and/or evaluation of participants. C.P.: review and critique; recruitment and/or evaluation of participants. K.J.: review and critique; recruitment and/or evaluation of participants. B.E.M.: review and critique; recruitment and/or evaluation of participants. S.M.: review and critique; recruitment and/or evaluation of participants. R.M.J.: review and critique; recruitment and/or evaluation of participants. V.C.: review and critique; recruitment and/or evaluation of participants. K.M.: review and critique; recruitment and/or evaluation of participants. d.F.O.: review and critique; recruitment and/or evaluation of participants. G.A.J.: review and critique; recruitment and/or evaluation of participants. O.C.: review and critique; recruitment and/or evaluation of participants. L.D.L.: review and critique; recruitment and/or evaluation of participants. MD: review and critique; review of english style. M.-M.P.: review and critique; supervision. M.P.: review and critique; recruitment and/or evaluation of participants.

\section{COMPETING INTERESTS}

Santos García D. has received honoraria for educational presentations and advice service by Abbvie, UCB Pharma, Lundbeck, KRKA, Zambon, Bial, Italfarmaco, and Teva. De Deus Fonticoba T: None. Cores $C$. has received honoraria for educational presentations and advice service by Lundbeck and UCB Pharma. Muñoz G: None. Paz González JM. has received honoraria for educational presentations and/or advice service by UCB Pharma, Lundbeck, KRKA, and Zambon. Martínez Miró C: None. Suárez E: None. Jesús S. has received honoraria from AbbVie, Bial, Merz, UCB, and Zambon and holds the competitive contract "Juan Rodés" supported by the Instituto de Salud Carlos III. She has received grants from the Spanish Ministry of Economy and Competitiveness (PI18/01898) and the Consejería de Salud de la Junta de Andalucía (PI-0459-2018). Aguilar M: UCB and Schwabe with assistance to a Congress; Nutricia with assistance to a Congress and payment of lecture. Pastor P: None. Planellas LL. has received travel bursaries grant from Abbvie. Cosgaya M: None. García Caldentey J. has received honoraria for educational presentations and advice service by Qualigen, Nutricia, Abbvie, Italfarmaco, UCB Pharma, Lundbeck, Zambon, Bial, and Teva. Caballol N. has received honoraria from Bial, Italfármaco, Qualigen, Zambon, UCB, Teva and KRKA and sponsorship from Zambon, TEVA and Abbvie for attending medical conferences. Legarda I. has received honoraria for educational presentations and advice service by Abbvie, UCB Pharma, Zambon, Bial, and Teva. Hernández Vara J. has received travel bursaries and educational grants from Abbvie and has received honoraria for educational presentations from Abbvie, Teva, Bial, Zambon, Italfarmaco, and Sanofi-Genzyme. Cabo I. has received honoraria for educational presentations and advice service by Abbvie, Zambon and Bial. López Manzanares L: Compensated advisory services, consulting, research grant support, or speaker honoraria: AbbVie, Acorda, Bial, Intec Pharma, Italfarmaco, Pfizer, Roche, Teva, UCB, and Zambon. González Aramburu I: None. Ávila Rivera MA. has received honoraria from Zambon, UCB Pharma, Qualigen, Bial, and Teva, and sponsorship from Zambon and Teva for attending conferences. Catalán MJ: None. Nogueira V: None. Puente V. has served as consultant for Abbvie and Zambon; has received grant/research from Abbvie. Ruíz de Arcos M: None. Borrué C: None. Solano Vila B. has received honoraria for educational presentations and advice service by UCB, Zambon, Teva, Abbvie, Bial. Álvarez Sauco M. has received honoraria for educational presentations and advice service by Abbvie, UCB Pharma, Zambon, Bial, and Teva. Vela L. has received honoraria for educational presentations and advice service by Abbvie, UCB Pharma, Lundbeck, KRKA, Zambon, Bial, and Teva. Escalante $S$. has received honoraria for educational presentations and advice service by Abbvie, Zambon, and Bial. Cubo E: Travel grants: Abbvie, Allergan, Boston; Lecturing honoraria: Abbvie, International Parkinson's disease Movement Disorder Society. Carrillo Padilla F. has received honoraria from Zambon (SEN Congress assistance). Martínez Castrillo JC. has received research support from Lundbeck, Italfarmaco, Allergan, Zambon, Merz, and Abbvie. He has received speaking honoraria from AbbVie, Bial, Italfarmaco, Lundbeck, Krka, TEVA, UCB, Zambon, Allergan, Ipsen, and Merz. Sánchez Alonso P. has received honoraria for educational presentations and advice service by Abbvie, UCB Pharma, Lundbeck, KRKA, Zambon, Bial, and Teva. Alonso Losada MG. has received honoraria for educational presentations and advice service by Zambon and Bial. López Ariztegui $\mathrm{N}$. has received honoraria for educational presentations and advice service by Abbvie, Italfarmaco, Zambon, and Bial. Gastón I. has received research support from Abbvie and Zambon and has served as a consultant for Abbvie, Exelts, and Zambon. Clavero P: Kulisevsky J: (1) Consulting fees: Roche, Zambon; (2) Stock / allotment: No; (3) Patent royalties / licensing fees: No; (4) Honoraria (e.g., lecture fees): Zambon, Teva, Bial, UCB; (5) Fees for promotional materials: No; (6) Research funding: Roche, Zambon, Ciberned; Instituto de SaludCarlos III; FundacióLa Maratóde TV3; (7) Scholarship from 
corporation: No; (8) Corporate laboratory funding: No; (9) Others (e.g., trips, travel, or gifts): No. Blázquez Estrada $M$. has received honoraria for educational presentations and advice service by Abbvie, Abbott, UCB Pharma, Allergan, Zambon, Bial, and Qualigen. Seijo M. has received honoraria for educational services from KRKA, UCB, Zambon, Bial; travel grants from Daiichi and Roche. Ruiz Martínez J. has received honoraria for educational presentations, attending medical conferences, and advice service by Abbvie, UCB Pharma, Zambon, Italfarmaco, Bial, and Teva. Valero C. has received honoraria for educational services from Zambon, Abbvie and UCB. Kurtis M. has received honoraria from Bial, the Spanish Neurology Society and the International and Movement Disorders Society. de Fábregues $\mathrm{O}$. has received honoraria for educational presentations and advice service by Bial, Zambon, Abbvie, KRKA, and Teva. González Ardura J. has recieved honoraria for speking from italofarma, Krka, Genzyme, UCB, Esteve, Psyma iberica marketing research SL and Ferrer, course grant from Teva and travel grant from Merck. Ordás C: None. López Díaz L. has received honoraria from UCB, Lundbeck, and KRKA. McAfee D: None. MartínezMartin P. has received honoraria from National School of Public Health (ISCIII), Editori-al Viguera and Takeda Pharmaceuticals for lecturing in courses; from Britannia for writing an article in their Parkinson's Disease Medical Journal-Kinetic; and from the International Parkinson and Movement Disorder Society (MDS) for management of the Program on Rating Scales. Grants: from the MDS for development and validation of the MDS-NMS. Mir P. has received honoraria from AbbVie, Abbott, Allergan, Bial, Merz, UCB and Zambon and have received grants from the Spanish Ministry of Economy and Competitiveness [PI16/01575] co-founded by ISCIII (Subdirección General de Evaluación y Fomento de la Investigación) and by Fondo Europeo de Desarrollo Regional (FEDER), the Consejería de Economía, Innovación, Ciencia y Empleo de la Junta de Andalucía [CVI-02526, CTS-7685], the Consejería de Salud y Bienestar Social de la Junta de Andalucía [PI-0437-2012, PI-04712013], the Sociedad Andaluza de Neurología, the Jacques and Gloria Gossweiler Foundation, the Fundación Alicia Koplowitz, the Fundación Mutua Madrileña.

\section{ADDITIONAL INFORMATION}

Supplementary information The online version contains supplementary material available at https://doi.org/10.1038/s41531-021-00256-w.

Correspondence and requests for materials should be addressed to SantosGarcía. D.

Reprints and permission information is available at http://www.nature.com/ reprints

Publisher's note Springer Nature remains neutral with regard to jurisdictional claims in published maps and institutional affiliations.

\begin{abstract}
Open Access This article is licensed under a Creative Commons adaptation, distribution and reproduction in any medium or format, as long as you give appropriate credit to the original author(s) and the source, provide a link to the Creative Commons license, and indicate if changes were made. The images or other third party material in this article are included in the article's Creative Commons license, unless indicated otherwise in a credit line to the material. If material is not included in the article's Creative Commons license and your intended use is not permitted by statutory regulation or exceeds the permitted use, you will need to obtain permission directly from the copyright holder. To view a copy of this license, visit http://creativecommons. org/licenses/by/4.0/.
\end{abstract}

(c) The Author(s) 2021, corrected publication 2022

\section{COPPADIS STUDY GROUP}

Daniela A. Adarmes ${ }^{3}$, Marta Almeria ${ }^{5}$, Araceli Alonso Cánovas ${ }^{27}$, F. Alonso Frech ${ }^{16}$, Ruben Alonso Redondo ${ }^{41}$, Ignacio Álvarez ${ }^{5}$, Ángel Aneiros Díaz ${ }^{2}$, Sandra Arnáiz ${ }^{25}$, Sonia Arribas ${ }^{5}$, Arancha Ascunce Vidondo ${ }^{31}$, Noemí Bernardo Lambrich ${ }^{24}$, Helana Bejr-Kasem ${ }^{32}$, María A. Botí ${ }^{5}$, María T. Buongiorno ${ }^{5}$, Carolina Cabello González ${ }^{31}$, A. Cámara Lorenzo ${ }^{7}$, Héctor Canfield Medina ${ }^{2}$, Fátima Carrillo ${ }^{3}$, Elena Casas ${ }^{25}$, Ana Cortina Fernández ${ }^{2}$, Anna Cots Foraster ${ }^{21}$, Ane Crespo Cuevas ${ }^{18}$, Mónica Díez-Fairen ${ }^{5}$, Julio Dotor García-Soto ${ }^{19}$, Elena Erro ${ }^{31}$, Elena Estelrich Peyret ${ }^{21}$, Noelia Fernández Guillán ${ }^{2}$, Pedro Gámez ${ }^{25}$, Mercedes Gallego ${ }^{13}$, Cristina García Campos ${ }^{19}$, Jose M. García Moreno ${ }^{19}$, María P. Gómez Garre ${ }^{3}$, Vívtor Gómez Mayordomo ${ }^{16}$, Javier González Aloy ${ }^{21}$, Beatriz González García ${ }^{13}$, María J. González Palmás ${ }^{12}$, González Toledo, R. Gabriel ${ }^{26}$, Ana Golpe Díaz ${ }^{2}$, Mireia Grau Solá9 , Gemma Guardia ${ }^{5}$, Andrea Horta-Barba ${ }^{32}$, Daniel Idoate Calderón ${ }^{12}$, Jon Infante ${ }^{4,14}$, Carmen Labandeira ${ }^{29}$, Miguel A. Labrador ${ }^{3}$, Francisco Lacruz ${ }^{31}$, Melva Lage Castro ${ }^{12}$, Sonia Lastres Gómez ${ }^{12}$, Balbino López Seoane ${ }^{42}$, Sara Lucas del Pozo ${ }^{10}$, Yolanda Macías ${ }^{23}$, Marina Mata ${ }^{20}$, Gloria Martí Andres ${ }^{43}$, María J. Martí ${ }^{7}$, Maria T. Meitín ${ }^{17}$, Manuel Menéndez González ${ }^{33}$, Carlota Méndez del Barrio ${ }^{3}$, Javier Miranda Santiago ${ }^{25}$, Morales Casado, I. María ${ }^{30}$, Antonio Moreno Diéguez ${ }^{2}$, Alba Novo Amado ${ }^{42}$, Sabela Novo Ponte ${ }^{28}$, Javier Pagonabarraga ${ }^{32}$, Isabel Pareés ${ }^{36}$, Berta Pascual-Sedano ${ }^{32}$, Aída Pérez Fuertes ${ }^{2}$, Rafael Pérez Noguera ${ }^{19}$, Ana Planas-Ballvé ${ }^{9}$, Marian A. Prats ${ }^{21}$, Cristina Prieto Jurczynska ${ }^{38}$, Mercedes Pueyo Morlans ${ }^{26}$, Arnayu Puig Davi ${ }^{32}$, Nuria Redondo Rafales ${ }^{13}$, Luisa Rodríguez Méndez ${ }^{2}$, Amparo B. Rodríguez Pérez ${ }^{22}$, Florinda Roldán ${ }^{3}$, Macarena Sánchez-Carpintero ${ }^{2}$, Gemma Sánchez Díez ${ }^{27}$, Antonio Sánchez Rodríguez ${ }^{14}$, Pilar Santacruz ${ }^{7}$, José C. Segundo Rodríguez ${ }^{30}$, María Sierra Peña ${ }^{14}$, Juan P. Tartari ${ }^{5}$, Laura Vargas ${ }^{3}$, Clara Villanueva $^{16}$, Bárbara Vives $^{10}$ and María D. Villar $^{26}$

${ }^{41}$ Hospital Universitario Lucus Augusti (HULA), Lugo, Spain. ${ }^{42}$ Hospital General Juan Cardona, Ferrol, A Coruña, Spain. ${ }^{43}$ Clínica Universidad de Navarra, Pamplona, Spain. 